\title{
Assessment of different thresholds of birthweight discordance for early neonatal outcomes: retrospective analysis of 2348 twin pregnancies
}

Shaoxin Ye ${ }^{1,2}$, Dazhi Fan ${ }^{1,2}$, Pengsheng Li ${ }^{1,2}$, Gengdong Chen ${ }^{1,2}$, Jiaming Rao ${ }^{1,2}$, Huishan Zhang ${ }^{1,2}$, Zixing Zhou ${ }^{1,2}$, Jinping Feng ${ }^{2}$, Caihong Luo ${ }^{2}$, Xiaoling Guo ${ }^{1,2}$, Zhengping Liu ${ }^{1,2^{*}}$ and Dongxin Lin ${ }^{1,2^{*}}$

\begin{abstract}
Background: The optimal threshold of birthweight discordance (BWD) remains controversial. This study aimed to evaluate the associations between BWD at different thresholds and early neonatal outcomes and to assess their predictive accuracy.

Methods: This was a retrospective cohort study using a birthweight data with the chorionicity information of 2348 liveborn twin pairs at a gestational age of $\geq 26$ weeks, from 2012 to 2018. The percentage of BWD was calculated by dividing the actual birthweight difference by the weight of the larger twin and multiplying by 100 . Outcomes of interest included neonatal intensive care unit (NICU) admission, neonatal respiratory distress syndrome (NRDS), ventilator support and a composite outcome combining major morbidities and neonatal death. Logistic regression models were performed to estimate the association between neonatal outcomes and BWD with different thresholds ( $\geq 15.0 \%$, $\geq 20.0 \%, \geq 25 \%$ and $\geq 30 \%$ ). Generalized estimated equation (GEE) models were used to address intertwin correlation. Restrictive cubic spline (RCS) models were established to draw the dose-response relationship between BWD and the odds ratios of outcomes. Clustered receiver operating characteristic (ROC) curve analyses were performed to assess the predictive accuracy.
\end{abstract}

Results: Of 2348 twin pairs, including 1946 dichorionic twin pairs and 402 monochorionic twin pairs, BWD was significantly associated with NICU admission, regardless of the thresholds used. The incidence of NRDS, ventilator support and the composite outcome were significantly higher when a threshold of $\geq 20 \%$ or greater was chosen. The dose-response relationship showed nonlinear growth in the risk of adverse neonatal outcomes with increasing BWD. ROC analyses showed a low significant AUROC of 0.569 (95\% Cl: 0.526-0.612) for predicting NICU admission but no significant AUROCs for predicting other outcomes. A BWD of $\geq 30 \%$ provided a moderate increase in the likelihood of $\mathrm{NICU}$ admission [positive likelihood ratio $\left(\mathrm{LR}^{+}\right)=5.77$ ].

\footnotetext{
*Correspondence: liuzphlk81@outlook.com; lindongxin21@outlook.com

2 Department of Obstetrics, Affiliated Foshan Maternity \& Child

Healthcare Hospital, Southern Medical University, Foshan 528000,

Guangdong, China

Full list of author information is available at the end of the article
} original author(s) and the source, provide a link to the Creative Commons licence, and indicate if changes were made. The images or other third party material in this article are included in the article's Creative Commons licence, unless indicated otherwise in a credit line to the material. If material is not included in the article's Creative Commons licence and your intended use is not permitted by statutory regulation or exceeds the permitted use, you will need to obtain permission directly from the copyright holder. To view a copy of this licence, visit http://creativecommons.org/licenses/by/4.0/. The Creative Commons Public Domain Dedication waiver (http://creativeco mmons.org/publicdomain/zero/1.0/) applies to the data made available in this article, unless otherwise stated in a credit line to the data. 
Conclusion: Although BWD is independently associated with adverse neonatal outcomes, it is not a single predictor for neonatal outcomes given the weak discriminative ability to predict neonatal outcomes. A cutoff of $30 \%$ is more practical for risk stratification among twin gestations.

Keywords: Birthweight discordance, Twin pregnancies, Neonatal outcome, Dose-response relationship, Predictive accuracy

\section{Background}

Twin pregnancies are well-known to be at increased risks of perinatal mortality and morbidity compared to singletons $[1,2]$. Growth discordance is a unique term used among pregnancies with twins or higher orders, and is usually monitored using estimated fetal weight (EFW) based on ultrasound examination in clinical practice [3]. Discordant growth to a certain degree may be inevitable, given that mild discordance may represent a normal variation between twin fetuses or an adaptation to limited intrauterine space [4]. However, severe growth discordance to a significant degree represents abnormal fetal growth and is associated with poor perinatal outcomes [5-7].

The optimal cutoff of significant discordant growth, beyond which a twin pregnancy may experience increased risks of adverse outcomes, remains controversial. Several thresholds are adopted in current literature and clinical practice ranging from 15 to $30 \%$. Among these threshold values, 20 and $25 \%$ are more commonly used [5, 6, 8-11]. A cutoff of $20 \%$ to define significant growth discordance is suggested by the American College of Obstetricians and Gynecologists [12] whereas a cutoff of $25 \%$ is suggested by the National Institute for Health and Care Excellence (NICE) guidance [13]. Previous studies used different cutoffs to evaluate the association between growth discordance and perinatal outcomes. However, the robustness of these results could be impeded by several limitations, including small sample size; lack of chorionicity information; use of EFW via ultrasound screening, which is less accurate; and ignorance of intertwin correlation in analyses [14-18]. Another question is whether discordant growth is clinically useful as a predictor of adverse outcomes. To the best of our knowledge, only a small number of studies assessed the predictive accuracy of growth discordance for predicting adverse outcomes and explored the optimum cutoff based on receiver operating characteristic (ROC) analyses $[5,9,19,20]$.

In the current study, we aimed to evaluate the associations between neonatal outcomes and BWD using different thresholds, based on birthweight data with chorionicity information. Additionally, we aimed to assess the ability of BWD to predict these outcomes.

\section{Methods}

\section{Study design}

This retrospective cohort study was performed at a tertiary hospital in Foshan, China, during the period from January 2012 to December 2018. All electric medical records of eligible subjects were systematically reviewed. This study was approved by the ethics committee of Southern Medical University Affiliated Maternal \& Child Health Hospital of Foshan, and informed consent from the patients was waived due to the retrospective design (ethics approval number: FSFY-20180903). All methods were performed in accordance with relevant guidelines and regulations.

\section{Inclusion and exclusion criteria}

Twin pregnancies with both liveborn fetuses at a gestational age of $\geq 26$ weeks were considered for inclusion. The exclusion criteria included congenital anomalies (except for persistent ductus arteriosus in cases of preterm birth), twin-to-twin transfusion (TTTS), fetal loss before 26 weeks and intrauterine death, monoamniotic twins and pregnancies with unknown chorionicity (Fig. 1).

\section{Data collection}

The following information was collected: maternal age, ethnicity, marital status, chorionicity, parity, use of assisted reproductive technology (ART), obstetric complications (e.g., gestational diabetes mellitus and pregnancy-related hypertensive disorder), mode of delivery, gestational age at delivery, neonatal sex and birthweight. Chorionicity was determined at the first sonographic examination and was confirmed by placental pathologic findings after birth, if available. For IVF/ICSI pregnancies the gestational age was calculated from the date of embryo transfer (+14days). For spontaneous pregnancies, the gestational age was calculated based on the last menstrual period and was further confirmed by sonography in the first trimester. The percentage of birthweight discordance (BWD) was calculated by dividing the actual birthweight difference by the weight of the larger twin and multiplying by 100 . Small for gestational age (SGA) was defined when the birth weight was below the 10th percentile for gestational age and sex based on twin birth weight curves in Chinese twins [21,22]. 


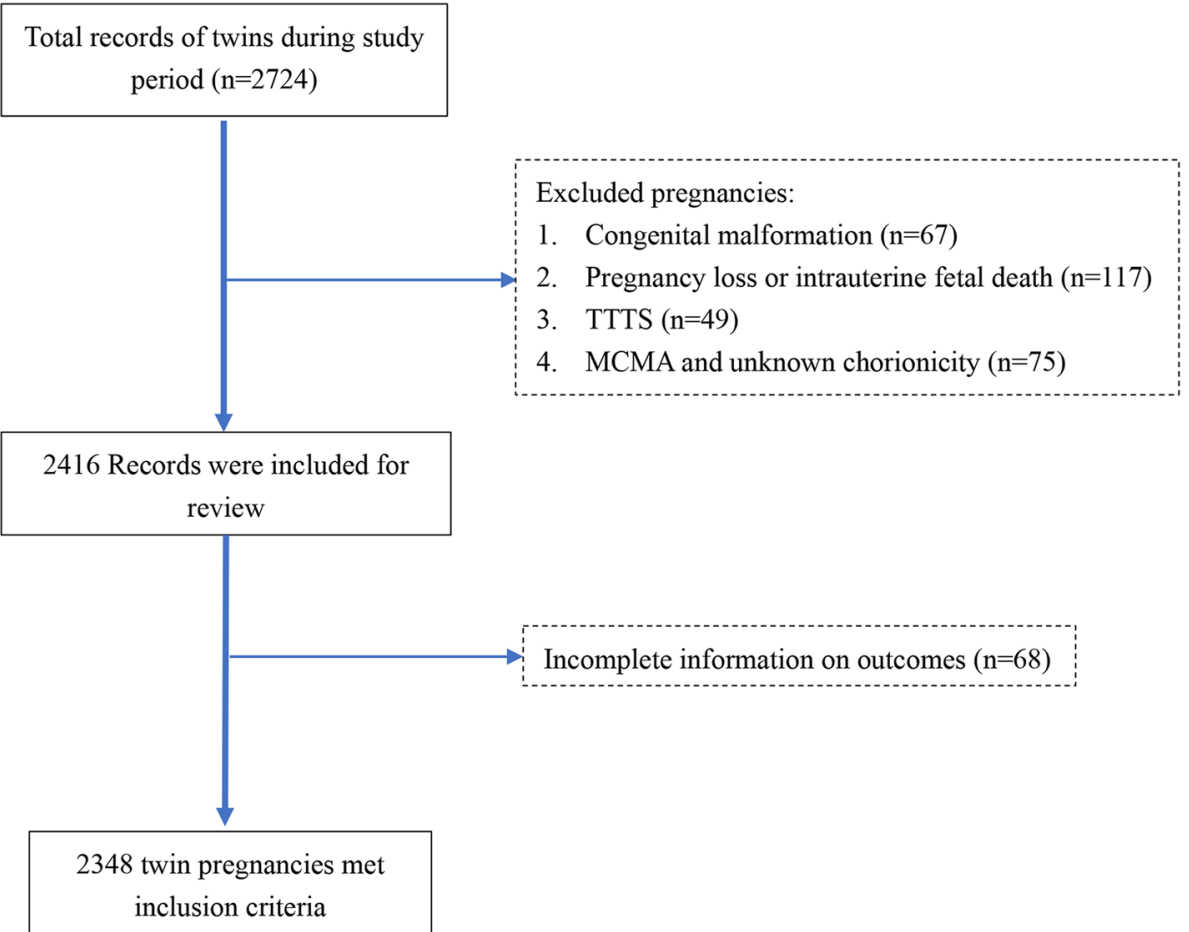

Fig. 1 Flow diagram of the inclusion of subjects in analysis

\section{Outcomes of interest}

The primary outcome of interest was neonatal intensive care unit (NICU) admission, whereas secondary outcomes included neonatal respiratory distress syndrome (NRDS) and ventilator support. We also defined a composite outcome as any occurrence of the following major morbidities and mortality: hypoxic-ischemic encephalopathy (HIE), bronchopulmonary dysplasia (BPD), necrotizing enterocolitis (NEC), intracranial hemorrhage (ICH), culture-proven sepsis and neonatal death within 28 days after birth.

\section{Statistical analysis}

All statistical analyses were performed using Stata, version 15.1 (Stata Corp, College Station, TX). Baseline characteristics were compared between five BWD groups determined based on the selected thresholds $(<15.0$, $15.0-19.9 \%, 20.0-24.9 \%, 25.0-29.9 \%$ and $\geq 30.0 \%$ ). Continuous variables are presented as the mean \pm standard deviation (SD), whereas categorical variables are presented as frequencies with their accompanying percentages. Differences were examined by using analysis of variance (ANOVA) for continuous variables and the chisquare test or Fisher's exact test for categorical variables.

To assess the association between the neonatal outcomes and BWD defined by the selected cutoffs, univariable logistic regression models were first performed to obtain crude odds ratios (ORs) and 95\% confidence intervals (CIs). Multivariable logistic regression models were further performed to control for confounders. In this procedure, two multivariable models were performed. Model 1 adjusted for the use of ART, nulliparity, chorionicity and gestational age. Model 2 further adjusted for SGA status. Generalized estimated equation (GEE) analysis was utilized to account for the withinpair effect. Logistic regression models stratified by chorionicity and larger/smaller twins were also performed. Restrictive cubic spline (RCS) models were conducted to establish the dose-response relationship between continuous BWD and the adjusted ORs of neonatal outcomes. Clustered ROC curve analysis, adjusted for confounders, was performed to determine the optimal threshold of BWD and to assess its predictive accuracy. The sensitivity, specificity, positive/negative predictive value (PPV and NPV), and positive/negative likelihood ratio $\left(\mathrm{LR}^{+}\right.$ and $\mathrm{LR}^{-}$) of each cutoff were calculated. An $\mathrm{LR}^{+}$of $>10$ indicates a significant increase in the likelihood of disease, whereas an $\mathrm{LR}^{+}$ranging from 5 to 10 and below 5 indicates a moderate and minimal increase, respectively [5]. The adjusted area under the ROC curve (AUROC) was also calculated. Confidence interval estimates were obtained from 1000 bootstrap replications. An AUROC 
curve of 0.5 indicates no discrimination, whereas an AUROC curve of 1.0 indicates perfect discrimination. All $P$-values were two-sided at a significance level of 0.05 .

\section{Results}

A total of 2348 pairs of twins, including 1946 dichorionic twin pairs and 402 monochorionic twin pairs, met the inclusion criteria. The numbers of pregnancies with BWDs of $<15.0 \%, \quad 15.0-19.9,20.0-24.9 \%, 25-29.9 \%$ and $\geq 30.0 \%$ were $1799,251,143,85$ and 75 , respectively. Characteristics based on BWD groups are shown in Table 1. Significant differences in chorionicity, nulliparity, pregnancy-related hypertensive disorder and SGA were noted between the five BWD groups (all $P<0.05$ ). Twins with severe BWD ( $\geq 30.0 \%)$ were delivered at earlier gestational ages than those with lower-level BWD $(P=0.003)$.

The ORs and 95\% CIs for different BWD thresholds obtained from univariable and multivariable logistic regressions are shown in Table 2. In general, we found that twins with BWD were at significantly increased risk of NICU admission irrespective of the thresholds. Overall, there was an increasing trend in the odds ratios of NICU admission with increasing BWD cutoffs. Although the adjusted ORs became lower when the SGA status was further controlled than before (Model 2), the values remained statistically significant. In terms of NRDS, significantly increased adjusted ORs were observed when a cutoff of $20 \%$ or greater was used. Similarly, twins with a BWD of $\geq 20 \%$ or greater were more likely to have ventilator support. After further adjusting for SGA status, however, the risk was only found in twins with BWD $\geq 30 \%$ (aOR: 2.39; 95\% CI: 1.25-4.57). Twins with BWD of $\geq 20 \%$ were also had an increased possibility experiencing composite outcomes. The results stratified by chorionicity are presented in Table S1. Overall, MCDA $(n=804)$ and DCDA twins $(n=3892)$ with BWD were associated with NICU admission irrespective of the cut-offs used. However, BWD was not associated with other outcomes in MCDA twins, but it was associated with other outcomes in DCDA twins when specific cutoffs were chosen (20, 25 and 30\%). The results stratified by the larger and smaller twins are shown in Table S2. Increased adjusted ORs of NICU admission were found in the larger twins when a cutoff of $20 \%$ or greater was used, whereas increased adjusted ORs were found in the smaller twin regardless of the cutoffs used. Furthermore, the larger twins in BWD pairs were associated with NRDS when a cutoff of $20 \%$ was used, whereas the smaller twins in BWD pairs were not associated with NRDS, regardless of the cutoff was used. The smaller twins in BWD pairs were more likely to have ventilator support when a cutoff of $30 \%$ was used and to have composite outcome when a cutoff of $25 \%$ or greater was used. In contrast, the larger twins in BWD pairs were not associated with ventilator support or composite outcome regardless of the cutoffs used. The RSC models, in which BWD was regarded as a continuous variable, showed nonlinear relationships between BWD and all the outcomes with adjustment for the use of ART, chorionicity, nulliparity and gestational age at delivery (Fig. 2). The odds ratio of NICU admission began to increase at a BWD of $20 \%$ (Fig. 2A). For NRDS and ventilator support, the curves were flatter. These odds ratios became significant at a BWD $\geq 40 \%$ given the overlaps between the band of the confidential interval and the reference line (Fig. 2B and C). Regarding the composite outcome, the risk increased at a BWD of approximately $25 \%$ (Fig. 2D). Stratified analyses showed

Table 1 Comparison of characteristics between twin pregnancies with different degrees of growth discordance

\begin{tabular}{|c|c|c|c|c|c|c|}
\hline Variables & $\begin{array}{l}<15.0 \% \\
(n=1799)\end{array}$ & $15.0-19.9 \%(n=251)$ & $\begin{array}{l}20.0-24.9 \% \\
(n=143)\end{array}$ & $\begin{array}{l}25.0-29.9 \% \\
(n=85)\end{array}$ & $\begin{array}{l}\geq 30.0 \% \\
(n=70)\end{array}$ & $P$-value \\
\hline Advanced maternal age ( $\geq 35$ years) & $376(20.9)$ & $58(23.1)$ & $27(18.9)$ & $13(15.3)$ & $17(24.3)$ & 0.526 \\
\hline Han ethnic & $1767(98.2)$ & $248(98.8)$ & $140(97.9)$ & $84(98.8)$ & 69 (98.6) & $0.965^{*}$ \\
\hline Not married & $38(2.1)$ & $6(2.4)$ & $4(2.8)$ & $4(4.7)$ & $1(1.4)$ & $0.499^{*}$ \\
\hline Monochorionic pregnancies & $305(17.0)$ & $41(16.3)$ & $25(17.5)$ & $10(11.8)$ & $21(30.0)$ & 0.039 \\
\hline ART conceived pregnancies & $1150(63.9)$ & $177(70.5)$ & $101(70.6)$ & $58(68.2)$ & $41(58.6)$ & 0.094 \\
\hline Nulliparity & $1213(67.4)$ & $179(71.3)$ & $113(79.0)$ & $70(82.4)$ & $51(72.9)$ & 0.002 \\
\hline Cesarean section & $1755(97.6)$ & $249(99.2)$ & $140(97.9)$ & $84(98.8)$ & $67(95.7)$ & 0.306 \\
\hline Gestational age at delivery (weeks) & $35.6 \pm 2.1$ & $35.3 \pm 2.3$ & $35.6 \pm 2.0$ & $35.0 \pm 2.5$ & $31.7 \pm 6.4$ & 0.003 \\
\hline Gestational diabetes mellitus & $341(19.0)$ & $59(23.5)$ & $26(18.2)$ & $13(15.3)$ & $13(18.6)$ & 0.405 \\
\hline Pregnancy-related hypertensive disorder & $164(9.1)$ & $34(13.6)$ & $23(16.1)$ & $11(12.9)$ & $20(28.6)$ & $<0.001$ \\
\hline Same sex & $1162(64.6)$ & $160(63.8)$ & $79(55.2)$ & $50(58.8)$ & $49(70.0)$ & 0.131 \\
\hline SGA in either twin & $129(7.2)$ & $45(17.9)$ & $48(33.6)$ & $51(60.0)$ & $62(88.6)$ & $<0.001$ \\
\hline
\end{tabular}

*Fisher's exact test 
Table 2 Association between neonatal outcomes and birthweight discordance by different cutoffs

\begin{tabular}{|c|c|c|c|c|c|c|}
\hline Outcomes & Crude OR & $P$-value & Adjusted OR & $P$-value & Adjusted OR & $P$-value \\
\hline \multicolumn{7}{|c|}{ NICU admission } \\
\hline$\geq 15 \%$ & $1.93(1.62-2.30)$ & $<0.001$ & $1.84(1.47-2.32)$ & $<0.001$ & $1.54(1.23-1.93)$ & $<0.001$ \\
\hline$\geq 20 \%$ & $2.55(2.03-3.21)$ & $<0.001$ & $2.71(2.03-3.64)$ & $<0.001$ & $1.83(1.37-2.44)$ & $<0.001$ \\
\hline$\geq 25 \%$ & $3.54(2.56-4.91)$ & $<0.001$ & $3.58(2.37-5.41)$ & $<0.001$ & $2.21(1.50-3.26)$ & $<0.001$ \\
\hline$\geq 30 \%$ & $6.05(3.49-10.51)$ & $<0.001$ & $6.33(3.2-12.53)$ & $<0.001$ & $2.44(1.37-4.36)$ & 0.002 \\
\hline \multicolumn{7}{|l|}{ NRDS } \\
\hline$\geq 15 \%$ & $1.31(0.97-1.77)$ & 0.077 & $1.10(0.73-1.65)$ & 0.655 & $1.06(0.70-1.60)$ & 0.780 \\
\hline$\geq 20 \%$ & $1.81(1.28-2.56)$ & 0.001 & $2.24(1.41-3.56)$ & 0.001 & $2.20(1.38-3.51)$ & 0.001 \\
\hline$\geq 25 \%$ & $2.39(1.57-3.62)$ & $<0.001$ & $2.39(1.38-4.16)$ & 0.002 & $2.32(1.32-4.09)$ & 0.004 \\
\hline$\geq 30 \%$ & $2.55(1.42-4.56)$ & 0.002 & $2.41(1.15-5.03)$ & 0.020 & $2.30(1.09-4.87)$ & 0.029 \\
\hline \multicolumn{7}{|c|}{ Ventilator support } \\
\hline$\geq 15 \%$ & $1.40(1.05-1.86)$ & 0.020 & $1.22(0.86-1.72)$ & 0.273 & $1.12(0.78-1.61)$ & 0.532 \\
\hline$\geq 20 \%$ & $1.59(1.13-2.24)$ & 0.007 & $1.67(1.11-2.51)$ & 0.014 & $1.51(0.98-2.33)$ & 0.059 \\
\hline$\geq 25 \%$ & $2.14(1.42-3.22)$ & $<0.001$ & $1.87(1.14-3.07)$ & 0.013 & $1.66(0.99-2.80)$ & 0.057 \\
\hline$\geq 30 \%$ & $2.77(1.61-4.77)$ & $<0.001$ & $2.66(1.43-4.96)$ & 0.002 & $2.39(1.25-4.57)$ & 0.009 \\
\hline \multicolumn{7}{|c|}{ Composite outcome } \\
\hline$\geq 15 \%$ & $1.44(0.88-2.33)$ & 0.145 & $1.37(0.82-2.27)$ & 0.228 & $1.28(0.76-2.14)$ & 0.355 \\
\hline$\geq 20 \%$ & $1.77(1.01-3.09)$ & 0.045 & $2.11(1.18-3.77)$ & 0.012 & $1.92(1.06-3.49)$ & 0.032 \\
\hline$\geq 25 \%$ & $2.80(1.51-5.18)$ & 0.001 & $2.88(1.50-5.56)$ & 0.002 & $2.58(1.30-5.13)$ & 0.007 \\
\hline$\geq 30 \%$ & $3.90(1.82-8.33)$ & $<0.001$ & $5.24(2.32-11.86)$ & $<0.001$ & $4.60(1.95-10.84)$ & $<0.001$ \\
\hline
\end{tabular}

a Model 1 adjusted for nulliparity, use of ART, chorionicity and gestational age

${ }^{\mathrm{b}}$ Model 2 adjusted for nulliparity, use of ART, chorionicity, gestational age and SGA status

different relationships between the odds ratios of NICU admission and BWD regrading DCDA/MCDA twins and smaller/larger twins (Fig. S1 and S2). The ORs were gradually higher among MCDA twins than DCDA twins, and higher among smaller twin than larger twins.

The clustered ROC curve analyses showed that BWD had a significant AUROC of 0.569 (95\% CI: 0.526-0.612) for predicting NICU admission but insignificant AUROCs for predicting NRDS, ventilator support and composite outcome (Fig. 3). In the stratified analysis, BWD had significant AUROCs for predicting NICU admission among DCDA (AUROC: 0.545; 95\% CI: 0.510-0.582) and MCDA (AUROC: 0.676; 95\% CI: 0.612-0.740) twins (Fig. S3 and S4) but did not have significant AUROCs for predicting other outcomes. BWD had a significant AUROC for predicting NICU admission among the smaller twins (AUROC: 0.615; 95\% CI: $0.570-0.659$ ) but not among the larger twins (AUROC: 0.525; 95\% CI: 0.403-0.533) (Fig. S5 and S6). We further calculated the diagnostic indices of selected thresholds of BWD for NICU admission, as shown in Table 3. Overall, the selected cutoffs showed a high specificity (ranging from 81.7 to $99.0 \%$ ) but a low sensitivity (ranging from 5.6 to $30.1 \%$ ) in predicting NICU admission. A BWD of $\geq 30 \%$ had an $\mathrm{LR}^{+}$of 5.77 , indicating a moderate increase in the likelihood of NICU admission. In contrast, other thresholds had a low $\mathrm{LR}^{+}$less than 5.0. In the stratified analyses, a BWD of $\geq 30 \%$ had an $\mathrm{LR}^{+}$greater than 5.0 in the subgroups of MCDA twins and smaller twins but had an $\mathrm{LR}^{+}$less than 5.0 in the subgroups of DCDA twins and larger twins.

\section{Discussion}

Based on the retrospective data of 2348 twin pairs, we found that birthweight discordance, regardless of the previously suggested thresholds (15, 20, 25 and 30\%), was associated with NICU admission. The risks of respiratory morbidity as well as those of composite outcome increased when a cutoff of $20 \%$ or greater was chosen. ROC analyses showed that the performance of BWD in predicting neonatal adverse outcomes was poor. Among these selected cutoffs, BWD $\geq 30 \%$ had the best accuracy for predicting NICU admission among twin pregnancies.

Prior studies evaluated perinatal morbidity and mortality between concordant and discordant twins, despite the selection of various cutoffs $[6,11,15,16,19,20,23-28]$. Finding an optimal threshold of discordant growth might benefit decision-making regarding the clinical management of twin gestations. Several limitations, including a lack of chorionicity data, small sample size and use of EFW, impede reaching a consensus on the optimal cutoff in clinical practice. In the current study, using the 

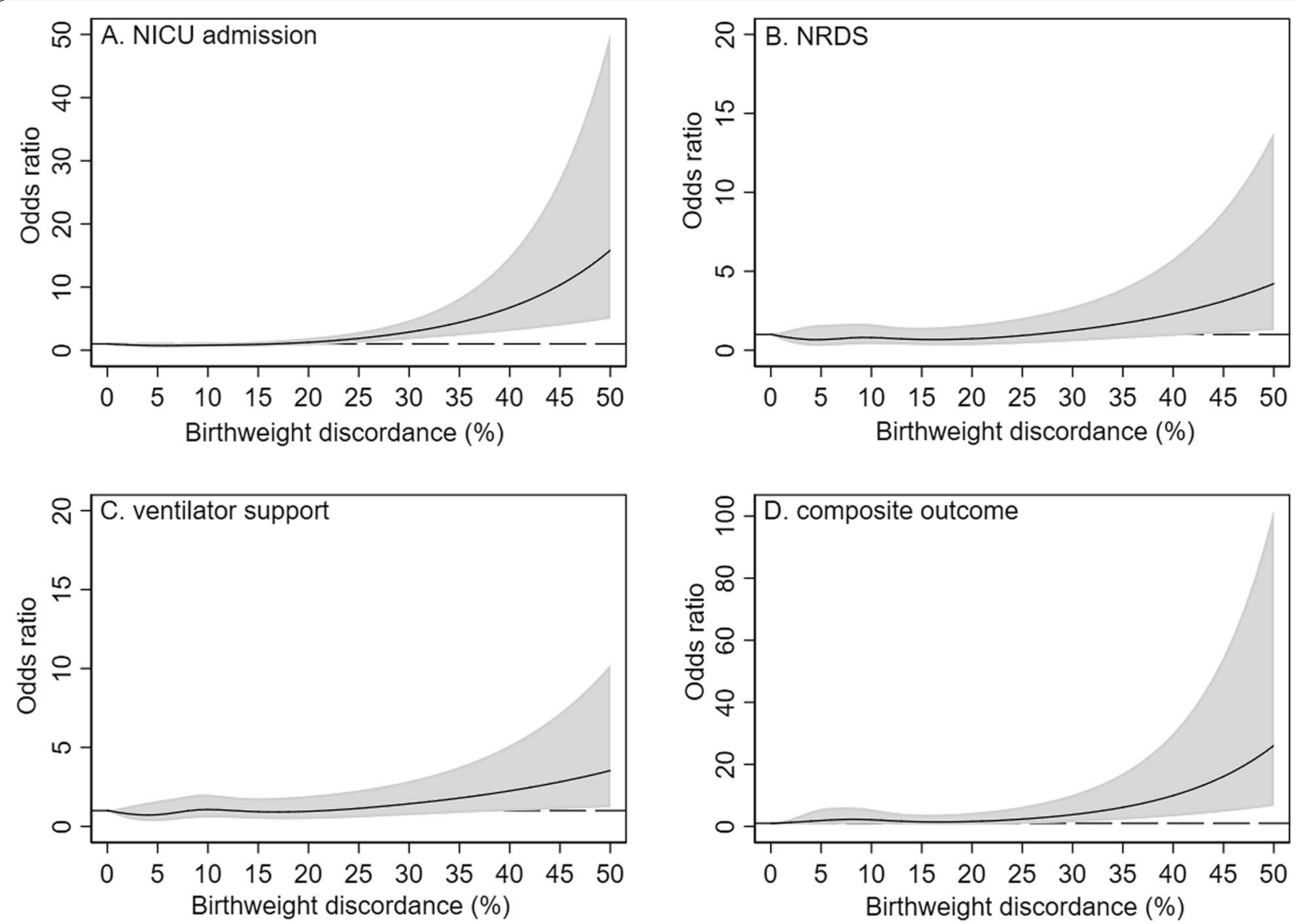

Fig. 2 The dose-response relationship between birthweight discordance and neonatal outcomes. Dashed lines represent the reference line $(\mathrm{OR}=1.0)$; gray bands represent $95 \%$ confidential intervals

retrospective data of 2348 twin pairs, we tried to evaluate selected cutoffs from the perspective of early neonatal outcomes. We found increased risks of NICU admission in twins with BWD despite the selected cutoffs. This finding was similar to that of $\mathrm{D}^{\prime}$ Antonio et al. [19]. However, they found no significant risk of NICU admission among twins with BWD $\geq 15 \%$ in an adjusted model. One possible explanation could be the more stringent inclusion criteria for gestational age at delivery in $\mathrm{D}^{\prime}$ Antonio et al.s study compared with ours (34weeks vs. 28 weeks). In addition, this risk increased with the increasing cutoff, which was further confirmed by the RSC models. These results might be useful for risk stratification among twin pregnancies in clinical practice. In the current study population, twins with severe BWD had a higher incidence of SGA. The inherent risk of SGA fetuses could contribute to this situation. After we controlled for SGA, the risks remained significant but lower when compared with those unadjusted for SGA. This result was supportive of the previous finding of Amaru et al. [27]. These researchers found that even among appropriate for gestational age (AGA) twins, discordant birthweight $(\geq 20 \%)$ was associated with NICU admission. Another cohort of 895 dichorionic and 250 monochorionic AGA twin pairs, however, showed that the risk of NICU admission was not increased in discordant $(\geq 20 \%)$ dichorionic twins (RR, 1.5; 95\% CI, 1.0-2.3) but was increased in discordant monochorionic twins (RR, 2.9; 95\% CI, 2.0-4.3) [29]. Unfortunately, the researchers did not take the intertwin correlation into account. We found that the ORs of NICU admission were higher among MCDA twins than DCDA twins. This result may be explained by the different pathophysiology of discordant growth between MCDA and DCDA twins, since the former have a shared placenta influencing both twin fetuses.

We also found increased respiratory morbidities, including NRDS and ventilator support, among BWD $(\geq 20 \%$ or greater) twins. This finding was inconsistent with some studies $[6,11,15,16,26,28]$ but supported by others $[27,30]$. This difference is probably due to significantly earlier gestational age among the twins with severe BWD given that they were usually associated with 


\section{A. NICU admission}
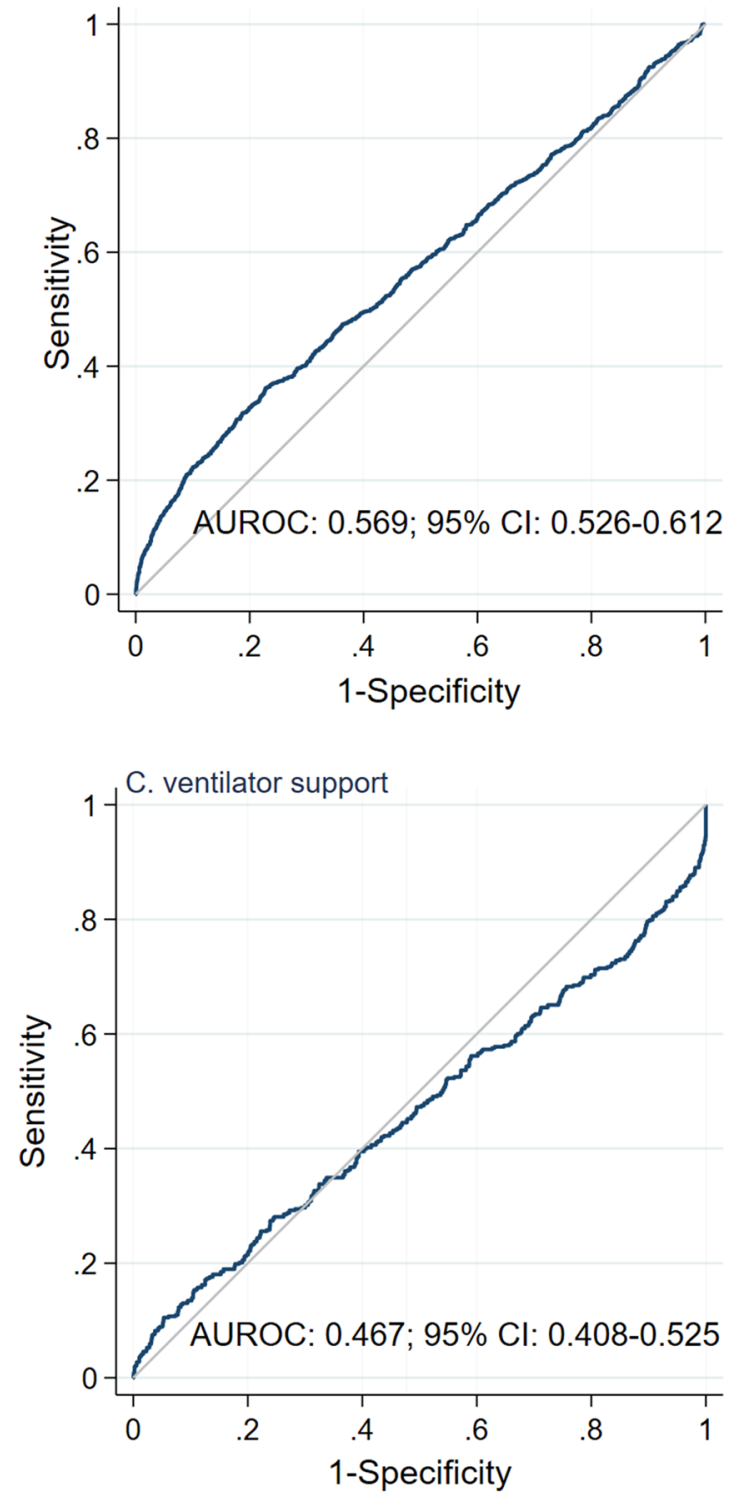

B. NRDS
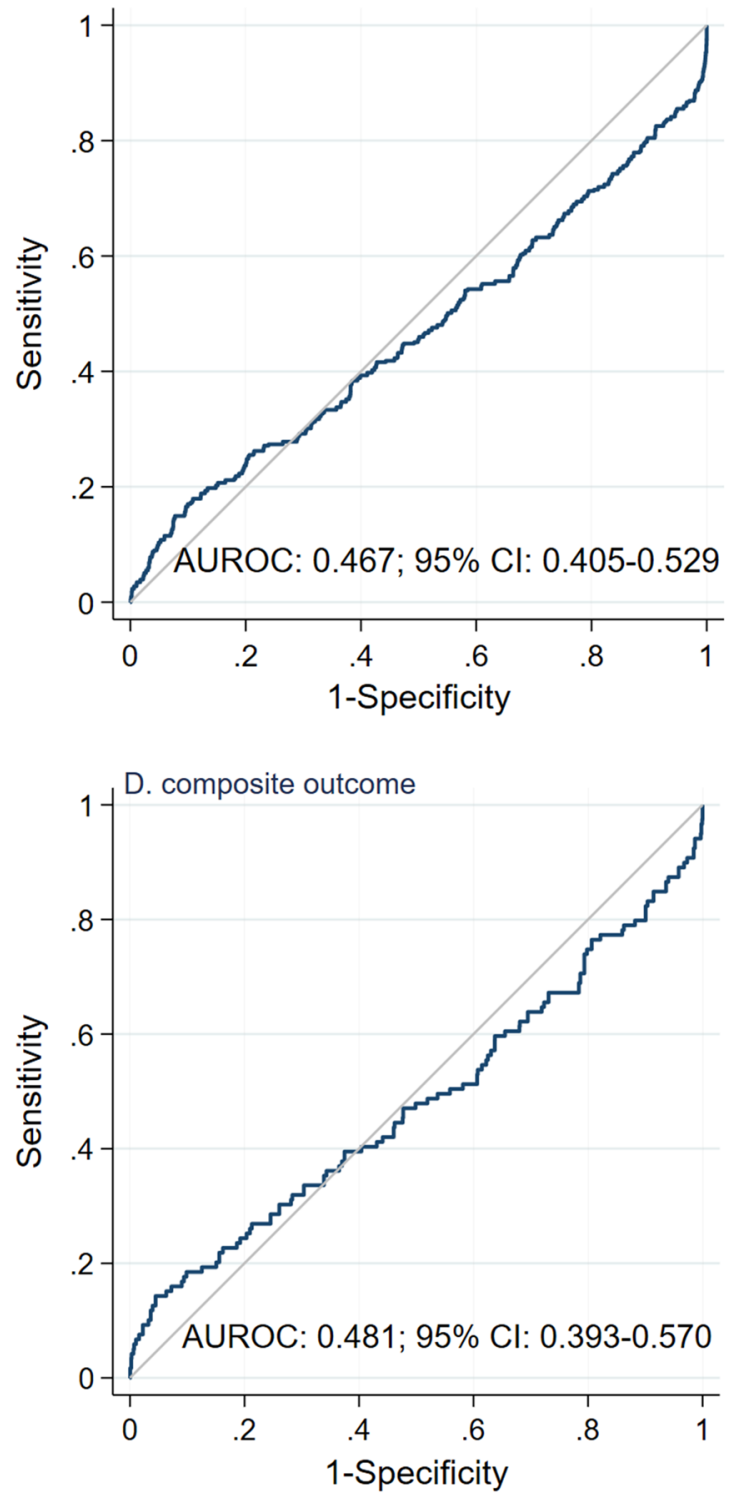

Fig. 3 ROC curve analysis of birthweight discordance for the prediction of neonatal outcomes

gestational hypertensive disorder $[15,16]$. Management of discordant twins is challenging. Increased surveillance and early delivery would benefit the survival of discordant twins since discordant growth was a contributor to intrauterine death in twins $[9,31,32]$. Preterm birth, however, remains the priority of adverse factors of neonatal prognosis. In this regard, the timing of delivery deserves to be further studied. Consistent with previous studies $[6,19$, 20], we defined a composite outcome containing major morbidity and neonatal death and found increased risk among twins with BWD ( $\geq 20 \%$ or greater). Given that the current literature lacks a validated composite index to measure neonatal morbidity, these results should be interpreted with caution.

Although BWD was associated with a significant increase in adverse neonatal outcomes, the ROC curve analysis obtained from our data suggested that BWD was unable to serve as a single predictor in clinical use (AUROC: 0.569; 95\% CI: 0.526-0.612). Similarly, Vergani et al. [20] reported an AUROC of $0.655 \pm 0.033$ among preterm twins. D'Antonio et al. [19] reported an AUROC of 0.58 (95\% CI: 0.53-0.63) among pregnancies beyond 34weeks of gestation. Jahanfar et al. [5] reported an AUROC of 0.54 (95\% CI: 0.51-0.56) among pregnancies 
Table 3 Sensitivity, specificity, positive and negative predictive value (PPV and NPV), and positive and negative likelihood ratio (LR and $L R^{-}$) of different cutoffs of birthweight discordance for prediction of NICU admission

\begin{tabular}{|c|c|c|c|c|c|c|}
\hline Cut-offs & Sensitivity & Specificity & PPV & NPV & $\mathbf{L R}^{+}$ & $\mathbf{L R}^{-}$ \\
\hline \multicolumn{7}{|l|}{ All twins } \\
\hline$\geq 15 \%$ & $30.1(28.1-32.2)$ & $81.7(80.2-83.2)$ & $55.6(52.6-58.6)$ & $60.6(59.0-62.2)$ & $1.65(1.49-1.83)$ & $0.85(0.83-0.88)$ \\
\hline$\geq 20 \%$ & $18.6(16.9-20.4)$ & $91.8(90.7-92.8)$ & $63.3(59.2-67.1)$ & $59.7(58.2-61.2)$ & $2.26(1.94-2.65)$ & $0.89(0.87-0.91)$ \\
\hline$\geq 25 \%$ & $10.9(9.6-12.4)$ & 96.7 (95.9-97.3) & $71.3(65.9-76.2)$ & $58.8(57.3-60.3)$ & $3.27(2.57-4.15)$ & $0.92(0.91-0.94)$ \\
\hline$\geq 30 \%$ & $5.6(4.7-6.7)$ & $99.0(98.6-99.3)$ & $81.4(73.8-87.3)$ & $58.0(56.5-59.4)$ & $5.77(3.78-8.80)$ & $0.95(0.94-0.96)$ \\
\hline \multicolumn{7}{|c|}{ MCDA twins } \\
\hline$\geq 15 \%$ & $34.8(30.3-39.6)$ & $87.5(83.7-90.6)$ & $75.3(68.5-81.0)$ & $55.2(51.2-59.2)$ & $2.79(2.08-3.75)$ & $0.74(0.69-0.80)$ \\
\hline$\geq 20 \%$ & $22.0(18.1-26.3)$ & $94.8(92.0-96.7)$ & $82.1(73.5-88.5)$ & $52.7(48.9-56.5)$ & $4.23(2.66-6.72)$ & $0.82(0.78-0.87)$ \\
\hline$\geq 25 \%$ & $13.4(10.3-17.1)$ & $98.4(96.5-99.4)$ & $90.3(79.5-96.0)$ & $51.1(47.4-54.7)$ & $8.58(3.74-19.68)$ & $0.88(0.85-0.91)$ \\
\hline$\geq 30 \%$ & $9.3(6.8-12.6)$ & $99.2(97.5-99.8)$ & $92.9(79.4-98.1)$ & $50.1(46.5-53.7)$ & $11.95(3.72-38.34)$ & $0.91(0.89-0.94)$ \\
\hline \multicolumn{7}{|c|}{ DCDA twins } \\
\hline$\geq 15 \%$ & $28.9(26.7-31.2)$ & $80.8(79.1-82.4)$ & $51.4(48.1-54.7)$ & $61.7(59.9-63.5)$ & $1.50(1.34-1.68)$ & $0.88(0.85-0.91)$ \\
\hline$\geq 20 \%$ & $17.7(15.9-19.7)$ & $91.3(90.0-92.4)$ & $58.9(54.3-63.3)$ & $61.2(59.5-62.8)$ & $2.03(1.72-2.41)$ & $0.90(0.88-0.92)$ \\
\hline$\geq 25 \%$ & $10.3(8.8-11.9)$ & $96.4(95.5-97.1)$ & $66.5(60.2-72.3)$ & $60.4(58.8-62.0)$ & $2.82(2.18-3.64)$ & $0.93(0.92-0.95)$ \\
\hline$\geq 30 \%$ & $4.7(3.7-5.8)$ & $99.0(98.5-99.3)$ & $76.5(66.7-84.3)$ & $59.6(58.0-61.1)$ & $4.63(2.91-7.35)$ & $0.96(0.95-0.97)$ \\
\hline \multicolumn{7}{|c|}{ Larger twins } \\
\hline$\geq 15 \%$ & $27.2(24.4-30.1)$ & $79.3(77.0-81.3)$ & $47.5(43.3-51.8)$ & $61.1(58.8-63.4)$ & $1.31(1.13-1.52)$ & $0.92(0.88-0.96)$ \\
\hline$\geq 20 \%$ & $16.3(14-18.8)$ & $89.8(88.0-91.3)$ & $52.3(46.5-58.1)$ & $60.8(58.6-62.9)$ & $1.59(1.29-1.96)$ & $0.93(0.91-0.96)$ \\
\hline$\geq 25 \%$ & $9.7(7.9-11.8)$ & $95.5(94.3-96.5)$ & $60.0(51.8-67.7)$ & $60.5(58.4-62.5)$ & $2.17(1.59-2.96)$ & $0.95(0.93-0.97)$ \\
\hline$\geq 30 \%$ & $4.9(3.7-6.5)$ & $98.3(97.5-98.9)$ & $67.1(54.8-77.6)$ & $59.9(57.9-61.9)$ & $2.95(1.81-4.83)$ & $0.97(0.95-0.98)$ \\
\hline \multicolumn{7}{|c|}{ Smaller twins } \\
\hline$\geq 15 \%$ & $32.8(30.0-35.7)$ & $84.5(82.3-86.4)$ & $63.8(59.6-67.8)$ & $60.1(57.8-62.4)$ & $2.11(1.81-2.46)$ & $0.80(0.76-0.83)$ \\
\hline$\geq 20 \%$ & $20.7(18.3-23.3)$ & $94.0(92.5-95.2)$ & $74.2(68.7-79)$ & $58.7(56.5-60.8)$ & $3.44(2.69-4.40)$ & $0.84(0.82-0.87)$ \\
\hline$\geq 25 \%$ & $12.0(10.1-14.1)$ & 97.9 (96.9-98.6) & $82.6(75.5-88.0)$ & $57.1(55-59.2)$ & $5.68(3.78-8.54)$ & $0.90(0.88-0.92)$ \\
\hline$\geq 30 \%$ & $6.3(4.9-7.9)$ & 99.8 (99.3-99.9) & $95.7(87.2-98.9)$ & $56.1(54-58.1)$ & $26.77(8.44-84.85)$ & $0.94(0.93-0.95)$ \\
\hline
\end{tabular}

beyond 20 weeks of gestation. Among these selected thresholds, a threshold of $\geq 30 \%$ was moderately predictable of NICU admission in twin gestations, suggesting that this cutoff was clinically practical. Interestingly, the results stratified by chorionicity showed that the AUROC was greater in MCDA twins than in DCDA twins (0.676 vs. 0.545), which suggested BWD was more predictable for NICU admission among MCDA twins. Moreover, the difference between AUROCs suggested that BWD was more predictable for NICU admission among the smaller twins than it was among the larger twins.

One of the strengths of the current study was largesized birthweight data with chorionicity information. Moreover, the use of GEE models accounting for intertwin correlation enables us to obtain robust results on associations between BWD and neonatal outcomes. Several limitations, nevertheless, should be considered when interpreting the current results. First, the retrospective nature of the study represents its main limitation. Birthweight was used to prevent the missing diagnosis of discordant twins. A recent prospective study using EFW by sonography suggested that the percentage of dichorionic twins exceeding a fixed discordance cutoff increased as gestation advanced [33]. Given this, caution should be taken when generalizing current results to those populations using estimated fetal weight based on sonography. Whether twins with EFW discordance at a lower level should be closely monitored deserves to be further discussed. Additionally, we were unable to exclude the possibility of confounders, such as fetuses with abnormal Doppler and the use of antennal corticosteroids, due to the lack of this information. The second limitation was the failure to detect differences in individual major morbidities due to the smaller number of events. Defining a composite measure might lack validity despite the increased power of analysis. Third, this study was based on a single-center database, therefore current results might be less generalized. Fourth, although gestational age was included for adjustment in the models, we could not provide stratified results according to gestational age since most of early preterm births attended NICU. 


\section{Conclusions}

Although BWD is independently associated with adverse neonatal outcomes among twin gestations, it could not serve as a single predictor for neonatal outcomes given the weak discriminative ability to predict neonatal outcomes. A cutoff of $30 \%$ is more practical for risk stratification among twin gestations.

\section{Abbreviations}

BWD: Birthweight discordance; NICU: Neonatal intensive care unit; NRDS: Neonatal respiratory distress syndrome; GEE: Generalized estimated equation; RCS: Restrictive cubic spline; ROC: Receiver operating characteristic; EFW: Estimated fetal weight; NICE: National Institute for Health and Care Excellence; TTTS: Twin-to-twin transfusion; ART: Assisted reproductive technology; SGA: Small for gestational age; HIE: Hypoxic-ischemic encephalopathy; BPD: Bronchopulmonary dysplasia; NEC: Necrotizing enterocolitis; ICH: Intracranial hemorrhage; ANOVA: Analysis of variance; OR: Odds ratios; Cl: Confidence interval; LR + : Positive likelihood ratio; LR-: Negative likelihood ratio; AUROC: Area under the ROC curve.

\section{Supplementary Information}

The online version contains supplementary material available at https://doi. org/10.1186/s12884-022-04417-4.

\section{Additional file 1.}

\section{Acknowledgements}

We would like to thank statistical help from Mr. Mingyu Zhang (Department of Epidemiology, John Hopkins Bloomberg School of Public Health, Baltimore, Maryland, USA).

\section{Informed consent statement}

Due to the retrospective design of current study, informed consent statement was not requested by the ethical committee of Southern Medical University Affiliated Maternal \& Child Health Hospital of Foshan.

\section{Authors' contributions}

Conceptualization, Z. Liu and D. Lin; Methodology, D. Fan and S. Ye; Data collection, J. Rao, H. Zhang, Z. Zhou and J. Feng; Statistical analysis, D. Fan and P. Li; Interpretation, G. Chen and C. Luo; Manuscript drafting, S. Ye; Review and edit, D. Fan, and D. Lin; Supervision, Z. Liu and X. Guo. All the authors have approved the final manuscript.

\section{Funding}

This work was supported by Medical Science and Technology Foundation of Guangdong Province (No: C2019090).

\section{Availability of data and materials}

The datasets used or analyzed in current study are available from the corresponding author on reasonable requests.

\section{Declarations}

\section{Ethics approval and consent to participate}

This study was approved by the ethics committee of Southern Medical University Affiliated Maternal \& Child Health Hospital of Foshan (ethics approval number: FSFY-20180903). Due to the respective nature of current study, the consent from each subject were waived by the ethics committee of Southern Medical University Affiliated Maternal \& Child Health Hospital of Foshan. All personal identifiers were anonymized prior to analysis. All methods were carried out in accordance with relevant guidelines and regulations.

\section{Consent for publication}

Not applicable.

\section{Competing interests}

The authors declare no competing interest.

\section{Author details}

${ }^{1}$ Foshan Institute of Fetal Medicine, Affiliated Foshan Maternity \& Child Healthcare Hospital, Southern Medical University, 11 Renminxi Road, Foshan 528000, Guangdong, China. ${ }^{2}$ Department of Obstetrics, Affiliated Foshan Maternity \& Child Healthcare Hospital, Southern Medical University, Foshan 528000, Guangdong, China.

Received: 4 June 2021 Accepted: 19 January 2022

Published online: 01 February 2022

\section{References}

1. Hiersch L, Okby R, Freeman H, Rosen H, Nevo O, Barrett J, et al. Differences in fetal growth patterns between twins and singletons. J Maternal-Fetal \& Neonatal Med. 2018:1-201.

2. Walker AR, Waites BT, Caughey AB. Twins versus singleton pregnancies: outcomes in small for gestational age late preterm deliveries. J MaternalFetal \& Neonatal Med. 2018:1-6.

3. Leombroni M, Liberati M, Fanfani F, Pagani G, Familiari A, Buca D, et al. Diagnostic accuracy of ultrasound in predicting birth-weight discordance in twin pregnancy: systematic review and meta-analysis. Ultrasound Obstetrics \& Gynecology. 2017;50(4):442-50.

4. Blickstein I, Kalish RB. Birthweight discordance in multiple pregnancy. Twin Res. 2003;6(6):526-31.

5. S J, K L, E O-J: Optimal threshold for birth weight discordance: does knowledge of chorionicity matter? J Perinatol 2016, 36(9):704-712.

6. Vedel C, Oldenburg A, Worda K, Larsen H, Holmskov A, Andreasen $K R$, et al. Short- and long-term perinatal outcome in twin pregnancies affected by weight discordance. Acta Obstet Gynecol Scand. 2017;96(2):233-42.

7. Chen X, Zhou Q Xiao X, Li X. The value of ultrasound in predicting isolated inter-twin discordance and adverse perinatal outcomes. Arch Gynecol Obstet. 2019;299(2):459-68.

8. Lin D, Fan D, Wu S, Chen G, Li P, Ma H, et al. The effect of gestational weight gain on perinatal outcomes among Chinese twin gestations based on Institute of Medicine guidelines. BMC pregnancy and childbirth. 2019;19(1):262

9. D'Antonio F, Khalil A, Dias T, Thilaganathan B. Weight discordance and perinatal mortality in twins: analysis of the Southwest Thames obstetric research collaborative (STORK) multiple pregnancy cohort. Ultrasound in obstetrics \& gynecology : the official journal of the International Society of Ultrasound in Obstetrics and Gynecology. 2013:41(6):643-8.

10. Diaz-Garcia C, Bernard JP, Ville Y, Salomon LJ. Validity of sonographic prediction of fetal weight and weight discordance in twin pregnancies. Prenat Diagn. 2010;30(4):361-7.

11. Di Mascio D, Acharya G, Khalil A, Odibo A, Prefumo F, Liberati M. Birthweight discordance and neonatal morbidity in twin pregnancies: a systematic review and meta-analysis. Acta Obstet Gynecol Scand. 2019:98(10):1245-57.

12. Practice Bulletin No. 169: multifetal gestations: twin, triplet, and higherorder multifetal pregnancies. Obstet Gynecol. 2016;128(4):e131-46.

13. National Institute for health and care excellence: multiple pregnancy: the management of twin and triplet pregnancies in the antenatal period | information for the public |. NICE; 2011.

14. van de Waarsenburg MK, Hack KE, Rijpma RJ, Mulder EJ, Pistorius L, Derks JB. Ultrasonographic prediction of birth weight discordance in twin pregnancies. Prenat Diagn. 2015;35(9):906-12.

15. Jahanfar S, Lim K, Ovideo-Joekes E. Birth weight discordance and adverse perinatal outcomes. J Perinat Med. 2017;45(5):603-11.

16. NS B, S S, EF B, JE B, S S, WA C, a D: birth weight discordance in very low birth weight twins: mortality, morbidity, and neurodevelopment. J Perinatol: official journal of the California Perinatal Association 2019, 39(9):1229-1240

17. SF, F G, M P, MP DC, VDA, PI G, R L, AA Z, C R: Is growth-discordance in twins a substantial risk factor in adverse neonatal outcomes? Twin research and human genetics : the official journal of the International Society for Twin Studies 2011, 14(5):463-467. 
18. Haimovich Y, Ascher-Landsberg J, Azem F, Mandel D, Mimouni FB, Many A. Neonatal outcome of preterm discordant twins. J Perinat Med. 2011;39(3):317-22

19. D'Antonio F, Thilaganathan B, Laoreti A, Khalil A. Birth-weight discordance and neonatal morbidity in twin pregnancy: analysis of STORK multiple pregnancy cohort. Ultrasound Obstetr Gynecology. 2018:52(5):586-92

20. Vergani P, Locatelli A, Ratti M, Scian A, Pozzi E, Pezzullo JC, et al. Preterm twins: what threshold of birth weight discordance heralds major adverse neonatal outcome? Am J Obstet Gynecol. 2004;191(4):1441-5.

21. Zhang B, Cao Z, Zhang Y, Yao C, Xiong C, Zhang Y, et al. Birthweight percentiles for twin birth neonates by gestational age in China. Sci Rep. 2016;6:31290.

22. Dai L, Deng C, Li Y, Yi L, Li X, Mu Y, et al. Population-based birth weight reference percentiles for Chinese twins. Ann Med. 2017;49(6):470-8

23. Fumagalli M, Schiavolin P, Bassi L, Groppo M, Uccella S, De Carli A, et al. The impact of twin birth on early neonatal outcomes. Am J Perinatol. 2016;33(1):63-70.

24. Breathnach FM, MCAuliffe FM, Geary M, Daly S, Higgins JR, Dornan J, et al. Definition of intertwin birth weight discordance. Obstet Gynecol. 2011;118(1):94-103.

25. Alam Machado Rde C, Brizot Mde L, Liao AW, Krebs VL, Zugaib M. Early neonatal morbidity and mortality in growth-discordant twins. Acta Obstet Gynecol Scand. 2009;88(2):167-71.

26. Kim LH, Caughey AB, Yee LM, Cheng YW. Association between the degree of twin birthweight discordance and perinatal outcomes. Am J Perinatol. 2019;36(9):969-74.

27. Amaru RC, Bush MC, Berkowitz RL, Lapinski RH, Gaddipati S. Is discordant growth in twins an independent risk factor for adverse neonatal outcome? Obstet Gynecol. 2004;103(1):71-6.

28. Kilic M, Aygun C, Kaynar-Tuncel E, Kucukoduk S. Does birth weight discordance in preterm twins affect neonatal outcome? J Perinatol. 2006:26(5):268-72.

29. LM H, MAW, AO O, KA R, GA M, AG C: significance of growth discordance in appropriately grown twins. Am J Obstet Gynecol 2013, 208(5):393. e391-393.e395.

30. Nassar AH, Usta IM, Khalil AM, Aswad NA, Seoud MA. Neonatal outcome of growth discordant twin gestations. J Perinat Med. 2003;31(4):330-6.

31. $F D A, A O O, F P, a K, D B, M E F, M L, L M, G$ a: weight discordance and perinatal mortality in twin pregnancy: systematic review and metaanalysis. Ultrasound in obstetrics \& gynecology : the official journal of the International Society of Ultrasound in Obstetrics and Gynecology 2018, 52(1):11-23.

32. Mahony R, Mulcahy C, McAuliffe F, Herlihy CO, Carroll S, Foley ME. Fetal death in twins. Acta Obstet Gynecol Scand. 2011;90(11):1274-80.

33. Amyx MM, Albert PS, Bever AM, Hinkle SN, Owen J, Grobman WA, et al. Intrauterine growth discordance across gestation and birthweight discordance in dichorionic twins. Am J Obstet Gynecol. 2020;222(2):174 e171-10.

\section{Publisher's Note}

Springer Nature remains neutral with regard to jurisdictional claims in published maps and institutional affiliations.

Ready to submit your research? Choose BMC and benefit from:

- fast, convenient online submission

- thorough peer review by experienced researchers in your field

- rapid publication on acceptance

- support for research data, including large and complex data types

- gold Open Access which fosters wider collaboration and increased citations

- maximum visibility for your research: over $100 \mathrm{M}$ website views per year

At $\mathrm{BMC}$, research is always in progress.

Learn more biomedcentral.com/submissions 